\title{
Surgery of primary tumor improves the survival of newly diagnosed metastatic melanoma: a population-based, propensity-matched study
}

This article was published in the following Dove Medical Press journal: Cancer Management and Research

\author{
Dongxiao Zhang ${ }^{1,2}$ \\ Yinjun Dong ${ }^{3}$ \\ Xiubin Sun ${ }^{4}$ \\ Shuanghu Yuan ${ }^{2}$ \\ Jinming $\mathrm{Yu}^{2}$
}

'School of Medicine, Shandong University, Jinan, Shandong 250000 , China; ${ }^{2}$ Department of Radiation Oncology, Shandong Cancer Hospital Affiliated to Shandong University, Jinan, Shandong 250I 17, China;

${ }^{3}$ Department of Thoracic Surgery, Shandong Cancer Hospital Affiliated to Shandong University, Jinan, Shandong 2501 17, China; ${ }^{4}$ School of Public Health, Shandong University, Jinan, Shandong 250000, China
Correspondence: Jinming Yu Department of Radiation Oncology, Shandong Cancer Hospital Affiliated to Shandong University, 440 Jiyan Road, Jinan, Shandong 250I I7, China

Tel +8653187984729

Fax +86 53I 87984079

Email sdyujinming@I63.com

Shuanghu Yuan

Department of radiation Oncology, Shandong Cancer Hospital Affiliated to Shandong University, 440 Jiyan road, Jinan, Shandong 250117, China Tel +86 I38 5310 69I6 Email yuanshuanghu@sina.com
Background: For the melanoma patients who are with the primary tumor and metastatic disease concurrently (the newly diagnosed metastatic patients), the effect of primary tumor surgery on survival has never been discussed.

Objective: We sought to estimate this effect based on data from the Surveillance, Epidemiology, and End Results database.

Patients and methods: We identified patients with newly diagnosed metastatic melanoma from 2004 to 2015 . The effect of primary tumor surgery was assessed by using Cox proportional hazard regression modeling and propensity score matching.

Results: Eight thousand three hundred and forty-one patients who had been diagnosed with primary melanoma and metastatic disease at the same time were included in this analysis, of whom 2,554 (30.6\%) received primary tumor surgery. In multivariable analysis of the unmatched cohort, primary tumor surgery was an independent protective factor of overall survival (HR $=0.617,95 \%$ CI $0.565-0.674 ; P<0.001)$ and melanoma-specific survival $(\mathrm{HR}=0.599,95 \%$ CI $0.537-0.668 ; P<0.001)$. In the matched cohort, primary tumor surgery was still associated with better overall survival (13 vs 6 months, $P<0.001)$ and melanoma-specific survival (18 vs 6 months, $P<0.001)$.

Conclusion: Our results reveal the benefit of primary tumor surgery on the survival of patients with newly diagnosed metastatic melanoma and may fill in the gaps of guidelines for this population.

IRB: IRB approval is not required because the SEER data are freely accessible.

Keywords: melanoma, metastatic, surgery, survival, propensity score, Surveillance, Epidemiology, and End Results database, SEER

\section{Plain language summary}

Why was the study done? For the newly diagnosed stage IV melanoma patients, the necessity and effect of primary tumor surgery has never been discussed.

What did the researchers do and find? We assessed the effect of primary tumor surgery on survival using Cox proportional hazard regression modeling and stratified propensity score matching as well, based on data from the Surveillance, Epidemiology, and End Results (SEER) database. The results show that primary tumor surgery is significantly associated with better patients' survival.

What do these results mean? This study challenges the conventional view and may fill in the gap of the relevant knowledge in the guideline. 


\section{Introduction}

Malignant melanoma accounts for the vast majority of skin cancer deaths in the USA. ${ }^{1}$ For melanoma patients with distant metastasis, the overall survival (OS) was only 9 months before 2009 and has improved to about 10-17 months in the recent decade. ${ }^{2,6}$ Common treatment options for metastatic melanoma comprise surgery, systemic therapy and radiotherapy. In spite of the fact that the surgical resection of metastases is suggested to be conducive to survival, complete resection of metastases is feasible in only a small proportion of carefully selected patients with metastatic melanoma. ${ }^{3-5}$ As systematic treatment represented by immune checkpoint inhibitors and targeted therapy has been becoming more important in the treatment of metastatic melanoma, the status of surgery has diminished in the last decade..$^{6-8}$

The primary tumor surgery is an effective means to treat or even potentially cure early-stage melanoma. ${ }^{9}$ However, for the melanoma patients with the primary tumor and metastatic disease concurrently occurring at the time of diagnosis (newly diagnosed metastatic patients), the necessity and effect of primary tumor surgery has never been discussed. The benefit of primary tumor surgery in improving survival that had been observed in other metastatic malignancies, such as breast cancer, ${ }^{10-14}$ colorectal cancer, ${ }^{15-17}$ gastric cancer, ${ }^{18-20}$ renal cell cancer ${ }^{21}$ and so on, made us wonder whether there would be a similar effect on metastatic melanoma. The Surveillance, Epidemiology, and End Results (SEER) database provides diagnosis, firstcourse treatment (including primary tumor surgery) and prognostic information of a considerable number of tumor patients..$^{22}$ Besides, as SEER only provides information on initial diagnosis but not information of disease recurrence, all its cases are newly diagnosed, meaning that all stage IV patients from the SEER are in stage IV at new diagnosis. This makes it possible for us to study the impact of primary tumor surgery on the survival of the newly diagnosed stage IV patients.

The objective of this study was to assess the prognostic value of primary tumor surgery in metastatic melanoma patients after minimizing a potential case selection bias by using propensity score-matching analysis, based on data from the SEER database.

\section{Patients and methods}

\section{Data source and patient selection}

A query of the SEER registry using SEER*Stat 8.3.5 was performed to identify all stage IV patients diagnosed as malignant melanoma (ICD-O-3/WHO-2008 recode of "mela- noma of the skin") between the years 2004 and 2015, based on the 1973-2015 SEER research incidence data (November 2017 submission). ${ }^{23}$ The information on surgery of primary tumor and metastatic sites, survival time, cause of death and other characteristics was identified. The cases with unknown surgical status or survival time and those with secondary malignancies at diagnosis were removed from the analysis. The characteristics of patients and tumor included time of diagnosis, age, sex, race, marital status, primary tumor site, histologic type, TNM stage and ulceration. Primary sites of melanoma were stratified into face/head/neck, trunk, limbs and other/unknown sites. Histologic types were stratified into nodular melanoma, superficial spreading melanoma, spindle cell melanoma and others/unknown types. The T, $\mathrm{N}$ and $\mathrm{M}$ stages were defined based on the American Joint Committee on Cancer TNM classification system for melanoma (sixth edition, 2002).

\section{Statistical analyses}

Kaplan-Meier curves were used to compare both OS and melanoma-specific survival (MSS, ie, death caused by cutaneous melanoma) in surgery and non-surgery groups. To further analyze the prognostic value of primary tumor surgery, multivariate Cox proportional hazard models were also used identify the factors associated to patients' survival. Besides, we conducted stratified analysis to estimate the effect of primary tumor surgery before and after the year 2011 (2004-2010 and 2011-2015), respectively.

\section{Propensity score matching}

As the included patients were not randomized in this retrospective study, the unbalanced baseline characteristics may lead to selection bias, and hence influence the decision to treat with primary tumor surgery. ${ }^{24}$ To reduce this impact, a matched case-control analysis was conducted by using propensity score matching. By using the propensity scores estimated according to the baseline covariates listed in Table 1 , a matched dataset was created. Patients who received primary tumor surgery were matched to patients who did not receive the same, based on the calculated propensity scores with an algorithm of the nearest-neighbor 1:1 matching. ${ }^{25}$

Data analysis was performed using SPSS Statistics 20.0 (IBM Corporation, Armonk, NY, USA). The categorical variables are presented as percentages and numbers, and comparisons are made using $\chi^{2}$ tests. Log-rank tests were used to compare the difference in survival between patients in different groups. All tests were two-sided, and a $P$-value of $<0.05$ was considered statistically significant. 
Table I Baseline variables before and after propensity score matching

\begin{tabular}{|c|c|c|c|c|c|c|c|c|}
\hline \multirow[t]{2}{*}{ Characteristics } & \multicolumn{4}{|c|}{ Unmatched cohort $(n=8,34 I)$} & \multicolumn{4}{|c|}{ Matched cohort $(n=1,476)$} \\
\hline & $\begin{array}{l}\text { No primary } \\
\text { tumor } \\
\text { surgery } \\
(n=5,787)\end{array}$ & $\begin{array}{l}\text { Primary } \\
\text { tumor } \\
\text { surgery } \\
(n=2,554)\end{array}$ & $\chi^{2}$ & $P$-value & $\begin{array}{l}\text { No primary } \\
\text { tumor } \\
\text { surgery } \\
(n=738)\end{array}$ & $\begin{array}{l}\text { Primary } \\
\text { tumor } \\
\text { surgery } \\
(n=738)\end{array}$ & $\chi^{2}$ & P-value \\
\hline & Count (\%) & Count (\%) & & & Count (\%) & Count (\%) & & \\
\hline Year of diagnosis & & & 24.25 & $<0.001$ & & & 0.03 & 0.870 \\
\hline $2004-2010$ & $3,000(51.8)$ & $\mathrm{I}, 473(57.7)$ & & & 479 (64.9) & $482(65.3)$ & & \\
\hline $2011-2015$ & $2,787(48.2)$ & $\mathrm{I}, 08 \mathrm{I}(42.3)$ & & & $259(35.1)$ & $256(34.7)$ & & \\
\hline Sex & & & 0.00 & 0.996 & & & 1.00 & 0.317 \\
\hline Female & $\mathrm{I}, 80 \mathrm{I}(3 \mathrm{I} . \mathrm{I})$ & $795(3 \mathrm{I} . \mathrm{I})$ & & & $23 I(3 I .3)$ & $249(33.7)$ & & \\
\hline Male & $3,986(68.9)$ & $1,759(68.9)$ & & & $507(68.7)$ & $489(66.3)$ & & \\
\hline Age at diagnosis (years) & & & 17.50 & 0.001 & & & 2.16 & 0.540 \\
\hline$\leq 40$ & $314(5.4)$ & $181(7.1)$ & & & $46(6.2)$ & $50(6.8)$ & & \\
\hline $4 I-60$ & $\mathrm{I}, 647(28.5)$ & $779(30.5)$ & & & $225(30.5)$ & $235(31.8)$ & & \\
\hline $6 I-80$ & $2,806(48.5)$ & $\mathrm{I}, \mathrm{I} 32(44.3)$ & & & $327(44.3)$ & $334(45.3)$ & & \\
\hline$\geq 8 \mathrm{I}$ & $1,020(17.6)$ & $462(18.1)$ & & & $140(19.0)$ & $119(16.1)$ & & \\
\hline Race & & & 4.77 & 0.312 & & & 7.78 & 0.100 \\
\hline White & $5,569(96.2)$ & $2,464(96.5)$ & & & $705(95.5)$ & $717(97.2)$ & & \\
\hline Black & $89(1.5)$ & $45(1.8)$ & & & $13(1.8)$ & $10(1.4)$ & & \\
\hline $\begin{array}{l}\text { American Indian/Alaska } \\
\text { Native }\end{array}$ & $56(1.0)$ & $19(0.7)$ & & & $12(1.6)$ & $4(0.5)$ & & \\
\hline Asian or Pacific Islander & $59(1.0)$ & $17(0.7)$ & & & $6(0.8)$ & $2(0.3)$ & & \\
\hline Unknown & $14(0.2)$ & $9(0.4)$ & & & $2(0.3)$ & $5(0.7)$ & & \\
\hline Marital status & & & 10.88 & 0.004 & & & 7.46 & 0.024 \\
\hline Unmarried & $2,160(37.3)$ & $\mathrm{I}, 015(39.7)$ & & & $319(43.2)$ & $268(36.3)$ & & \\
\hline Married & $3,343(57.8)$ & $1,385(54.2)$ & & & $379(5 \mid .4)$ & $428(58.0)$ & & \\
\hline Unknown & $284(4.9)$ & $154(6.0)$ & & & $40(5.4)$ & $42(5.7)$ & & \\
\hline Primary site & & & $4,389.20$ & $<0.001$ & & & 7.21 & 0.066 \\
\hline Limbs & $290(5.0)$ & $835(32.7)$ & & & $211(28.6)$ & $182(24.7)$ & & \\
\hline Trunk & $307(5.3)$ & $8 \mid 2(3 \mid .8)$ & & & $218(29.5)$ & $196(26.6)$ & & \\
\hline Face/head/neck & $250(4.3)$ & $678(26.5)$ & & & $160(21.7)$ & $185(25.1)$ & & \\
\hline Other & $4,940(85.4)$ & $229(9.0)$ & & & $149(20.2)$ & $175(23.7)$ & & \\
\hline Histologic type & & & $\mathrm{I}, 70 \mathrm{I} .66$ & $<0.001$ & & & 0.25 & 0.969 \\
\hline SSM & $27(0.5)$ & $257(10.1)$ & & & $17(2.3)$ & $17(2.3)$ & & \\
\hline NM & $72(1.2)$ & $569(22.3)$ & & & $44(6.0)$ & $41(5.6)$ & & \\
\hline SCM & $110(1.9)$ & $64(2.5)$ & & & $13(1.8)$ & $15(2.0)$ & & \\
\hline Other/unknown & $5,578(96.4)$ & $\mathrm{I}, 664(65.2)$ & & & $664(90.0)$ & $665(90.1)$ & & \\
\hline T stage & & & $4,095.13$ & $<0.001$ & & & 3.25 & 0.517 \\
\hline $\mathrm{TI}$ & $73(1.3)$ & $332(13.0)$ & & & $35(4.7)$ & $34(4.6)$ & & \\
\hline $\mathrm{T} 2$ & $43(0.7)$ & $265(10.4)$ & & & $34(4.6)$ & $26(3.5)$ & & \\
\hline T3 & $5 I(0.9)$ & $382(15.0)$ & & & $44(6.0)$ & $36(4.9)$ & & \\
\hline $\mathrm{T} 4$ & $79(1.4)$ & 789 (30.9) & & & $56(7.6)$ & $69(9.3)$ & & \\
\hline Unknown & $5,54 \mid(95.7)$ & $786(30.8)$ & & & $569(77.1)$ & $573(77.6)$ & & \\
\hline $\mathrm{N}$ stage & & & $\mathrm{I}, 460.02$ & $<0.001$ & & & 5.13 & 0.274 \\
\hline No & $891(15.4)$ & $533(20.9)$ & & & $156(2 \mathrm{I} . \mathrm{I})$ & $141(19.1)$ & & \\
\hline $\mathrm{NI}$ & $\mathrm{I}, 835(31.7)$ & $\mathrm{I}, 048(4 \mathrm{I} .0)$ & & & $289(39.2)$ & $272(36.9)$ & & \\
\hline N2 & $85(1.5)$ & $248(9.7)$ & & & $40(5.4)$ & $52(7.0)$ & & \\
\hline N3 & $130(2.2)$ & $389(15.2)$ & & & $62(8.4)$ & $80(10.8)$ & & \\
\hline $\mathrm{Nx}$ & $2,846(49.2)$ & $336(13.2)$ & & & 19I (25.9) & $193(26.2)$ & & \\
\hline M stage & & & 310.70 & $<0.001$ & & & 2.73 & 0.256 \\
\hline Mla & $570(9.8)$ & $626(24.5)$ & & & $108(14.6)$ & $|3|(\mid 7.8)$ & & \\
\hline $\mathrm{MIb} / \mathrm{c}$ & $3,932(67.9)$ & $I, 47 \mid(57.6)$ & & & $45 I(6 I . I)$ & $430(58.3)$ & & \\
\hline$M x$ & $1,285(22.2)$ & $457(17.9)$ & & & $179(24.3)$ & $177(24.0)$ & & \\
\hline Ulceration & & & $3,007.38$ & $<0.001$ & & & 0.11 & 0.947 \\
\hline No & 676 (II.7) & $659(25.8)$ & & & $87(11.8)$ & 83 (II.2) & & \\
\hline Yes & $125(2.2)$ & $\mathrm{I}, 098(43.0)$ & & & $96(13.0)$ & $96(13.0)$ & & \\
\hline Unknown & $4,986(86.2)$ & $797(3 \mid .2)$ & & & 555 (75.2) & 559 (75.7) & & \\
\hline
\end{tabular}


Table I (Continued)

\begin{tabular}{|c|c|c|c|c|c|c|c|c|}
\hline \multirow[b]{2}{*}{ Characteristics } & \multicolumn{4}{|c|}{ Unmatched cohort $(n=8,34 I)$} & \multicolumn{4}{|c|}{ Matched cohort $(n=1,476)$} \\
\hline & $\begin{array}{l}\text { No primary } \\
\text { tumor } \\
\text { surgery } \\
(n=5,787)\end{array}$ & $\begin{array}{l}\text { Primary } \\
\text { tumor } \\
\text { surgery } \\
(n=2,554)\end{array}$ & $\chi^{2}$ & $P$-value & $\begin{array}{l}\text { No primary } \\
\text { tumor } \\
\text { surgery } \\
(n=738)\end{array}$ & $\begin{array}{l}\text { Primary } \\
\text { tumor } \\
\text { surgery } \\
(n=738)\end{array}$ & $\chi^{2}$ & $P$-value \\
\hline & Count (\%) & Count (\%) & & & Count (\%) & Count (\%) & & \\
\hline Metastasectomy & & & 3.80 & 0.051 & & & 0.63 & 0.429 \\
\hline No & $5,656(97.7)$ & $2,5 \mid 3(98.4)$ & & & $727(98.5)$ & $723(98.0)$ & & \\
\hline Yes & $|3|(2.3)$ & $4 I(1.6)$ & & & $\mathrm{II}(\mathrm{I} .5)$ & $15(2.0)$ & & \\
\hline
\end{tabular}

Abbreviations: NM, nodular melanoma; SCM, spindle cell melanoma; SSM, superficial spreading melanoma.

A

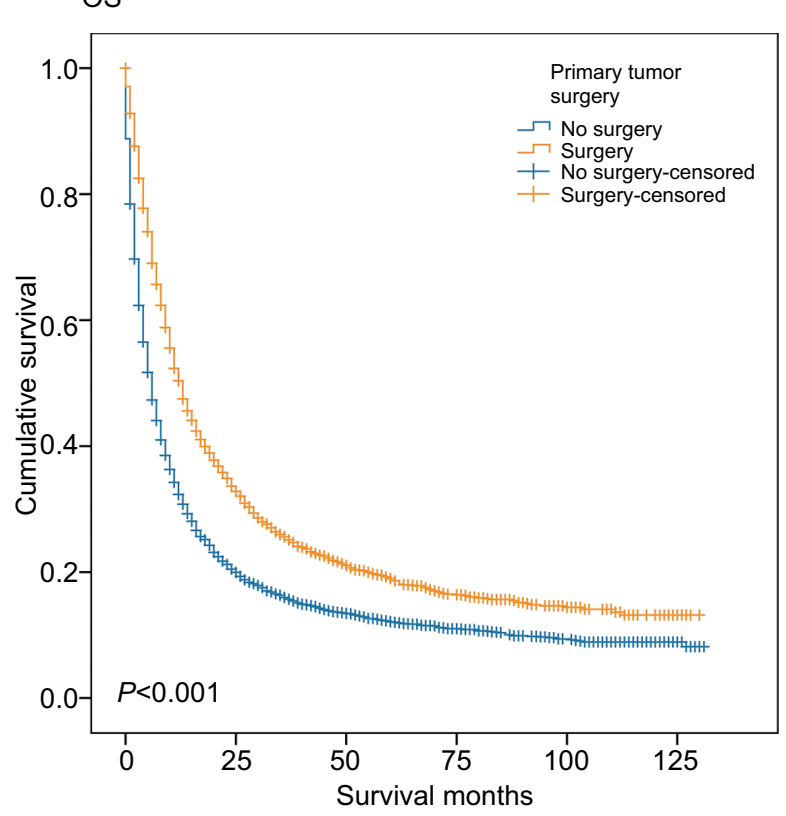

B

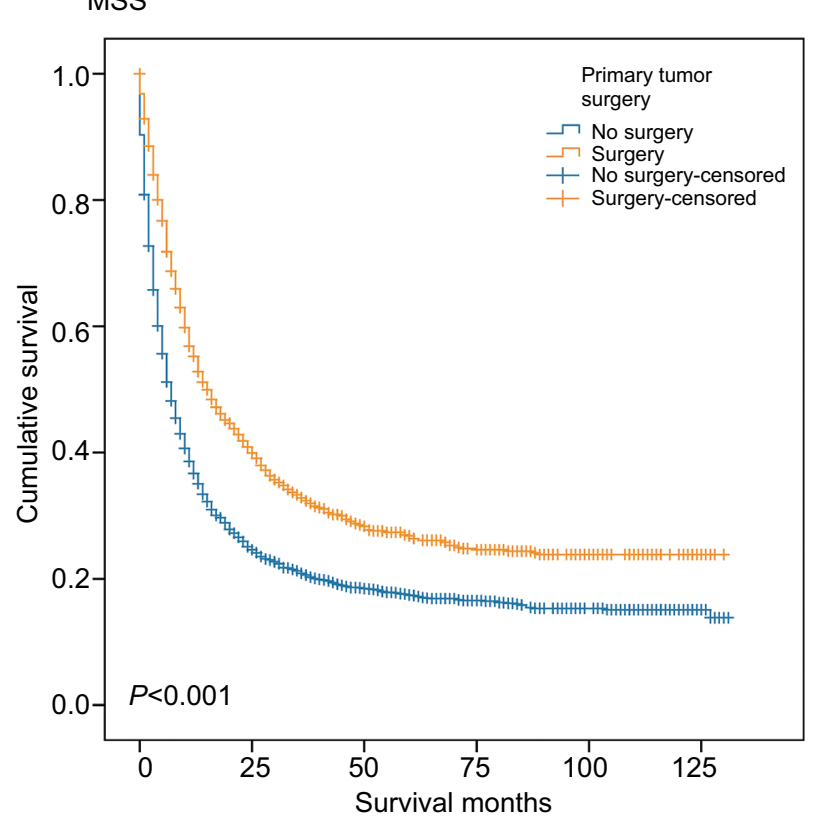

Figure I Kaplan-Meier curves for (A) OS and (B) MSS according to primary tumor surgery status in the unmatched cohort.

Abbreviations: MSS, melanoma-specific survival; OS, overall survival.

\section{Results}

Eight thousand three hundred and forty-one patients who had been diagnosed with primary melanoma and metastatic disease at the same time were included in this analysis, of which 2,554 (30.6\%) received surgery of the primary tumor and $2.1 \%$ received metastasectomy (Table 1 ). The median OS and MSS of all patients were 8.0 months $(95 \%$ CI 7.7-8.3 months) and 9.0 months (95\% CI 8.5-9.5 months), respectively.

On univariate analysis of the unmatched cohort, patients receiving surgery of the primary tumor had both better median OS ( 13 vs 6 months, $P<0.001)$ and median MSS ( 15 vs 7 months, $P<0.001)$, compared with those who did not receive the same (Figure 1). Besides, this trend occurred in both periods of 2009-2010 (OS: 12 vs 5 months; MSS: 13 vs 6 months) and 2011-2015 (OS: 14 vs 6 months; MSS: 22 vs 9 months), with all $P$-values being $<0.001$ (data not shown). On multivariable Cox regression analysis, undergoing primary tumor surgery was an independent protective factor of OS (HR $=0.617,95 \%$ CI $0.565-0.674 ; P<0.001)$ and MSS (HR $=0.599,95 \%$ CI $0.537-0.668 ; P<0.001)$, as shown in Table 2 . The other protective factors of OS included later years of diagnosis $(2011-2015$; $\mathrm{HR}=0.837,95 \% \mathrm{CI}$ 0.790-0.886; $P<0.001$ ), married status (HR $=0.770,95 \%$ CI $0.730-0.813 ; P<0.001)$ and metastasectomy $(\mathrm{HR}=0.466$, 95\% CI 0.381-0.570; $P<0.001)$, as shown in Table 2. The risk factors of OS included older age, sex of male, tumor location of trunk, historical type of nodular melanoma and higher T, $\mathrm{N}$ and $\mathrm{M}$ stages. The protective and risk factors of MSS were similar to those of OS. 
Table 2 Multivariate analysis of prognostic factors for survival in the unmatched population

\begin{tabular}{|c|c|c|c|c|c|c|c|}
\hline \multirow[t]{2}{*}{ Variables } & \multirow[t]{2}{*}{ Category } & \multicolumn{3}{|l|}{ os } & \multicolumn{3}{|l|}{ MSS } \\
\hline & & $P$-value & $\operatorname{Exp}(B)$ & $\begin{array}{l}95 \% \mathrm{Cl} \text { for } \\
\operatorname{Exp}(\mathrm{B})\end{array}$ & $P$-value & $\operatorname{Exp}(B)$ & $\begin{array}{l}95 \% \mathrm{Cl} \text { for } \\
\operatorname{Exp(B)}\end{array}$ \\
\hline Year of diagnosis & $2011-2015$ & $<0.001$ & 0.837 & $0.790-0.886$ & $<0.001$ & 0.704 & $0.656-0.75$ \\
\hline Sex & Male & $<0.001$ & 1.128 & $1.067-1.193$ & $<0.001$ & 1.151 & $1.076-1.231$ \\
\hline \multirow[t]{4}{*}{ Age at diagnosis (years) } & $\leq 40$ & $<0.001$ & & & $<0.001$ & & \\
\hline & $4 I-60$ & $<0.001$ & 1.229 & $1.091-1.385$ & 0.002 & 1.220 & $1.075-1.384$ \\
\hline & $61-80$ & $<0.001$ & 1.425 & $1.269-1.600$ & $<0.001$ & 1.321 & $1.166-1.497$ \\
\hline & $\geq 81$ & $<0.001$ & 1.924 & $1.700-2.178$ & $<0.001$ & 1.742 & $1.511-2.007$ \\
\hline \multirow[t]{3}{*}{ Marital status } & Unmarried & $<0.001$ & & & $<0.001$ & & \\
\hline & Married & $<0.001$ & 0.770 & $0.730-0.813$ & $<0.001$ & 0.732 & $0.686-0.78 \mid$ \\
\hline & Unknown & $<0.001$ & 0.692 & $0.610-0.785$ & $<0.001$ & 0.620 & $0.526-0.732$ \\
\hline \multirow[t]{4}{*}{ Primary site } & Limbs & $<0.001$ & & & $<0.001$ & & \\
\hline & Trunk & 0.036 & 1.110 & $1.007-1.223$ & 0.123 & 1.098 & $0.975-1.237$ \\
\hline & Face/head/neck & 0.196 & 0.933 & $0.840-1.036$ & 0.068 & 0.882 & $0.770-1.009$ \\
\hline & Other & 0.020 & 0.888 & $0.803-0.981$ & 0.007 & 0.847 & $0.750-0.957$ \\
\hline \multirow[t]{4}{*}{ Histologic type } & SSM & 0.001 & & & 0.001 & & \\
\hline & NM & 0.005 & 1.303 & $1.083-1.567$ & 0.004 & 1.390 & $1.112-1.739$ \\
\hline & SCM & 0.662 & 0.946 & $0.737-1.214$ & 0.704 & 0.942 & $0.69 \mathrm{I}-1.284$ \\
\hline & Other/unknown & 0.021 & 1.222 & $1.031-1.449$ & 0.022 & 1.273 & $1.035-1.564$ \\
\hline \multirow[t]{5}{*}{ T stage } & $\mathrm{TI}$ & 0.021 & & & \multirow{5}{*}{\multicolumn{3}{|c|}{$N / A^{a}$}} \\
\hline & $\mathrm{T} 2$ & 0.529 & 1.060 & $0.884-1.272$ & & & \\
\hline & T3 & 0.440 & 1.067 & $0.905-1.259$ & & & \\
\hline & $\mathrm{T} 4$ & 0.005 & 1.230 & $1.063-1.423$ & & & \\
\hline & Unknown & 0.632 & 1.035 & $0.899-1.192$ & & & \\
\hline \multirow[t]{5}{*}{$\mathrm{N}$ stage } & No & $<0.001$ & & & & & \\
\hline & $\mathrm{NI}$ & 0.001 & 1.139 & $1.052-1.233$ & 0.001 & 1.179 & $1.068-1.302$ \\
\hline & N2 & 0.924 & 1.007 & $0.865-1.174$ & 0.876 & 0.985 & $0.814-1.192$ \\
\hline & N3 & $<0.001$ & 1.337 & $1.182-1.511$ & $<0.001$ & 1.453 & $1.256-1.68 \mid$ \\
\hline & $\mathrm{Nx}$ & $<0.001$ & 1.279 & $1.186-1.379$ & $<0.001$ & 1.333 & $1.212-1.465$ \\
\hline \multirow[t]{3}{*}{ M stage } & $\mathrm{Mla}$ & $<0.001$ & & & $<0.001$ & & \\
\hline & $\mathrm{MIb} / \mathrm{c}$ & $<0.001$ & 2.191 & $2.013-2.383$ & $<0.001$ & 2.559 & $2.294-2.854$ \\
\hline & $M x$ & $<0.001$ & 1.875 & $1.705-2.06 \mathrm{I}$ & $<0.001$ & 2.119 & $1.876-2.393$ \\
\hline Primary tumor surgery & Yes & $<0.001$ & 0.617 & $0.565-0.674$ & $<0.001$ & 0.599 & $0.537-0.668$ \\
\hline Metastasectomy & Yes & $<0.001$ & 0.466 & $0.38 \mathrm{I}-0.570$ & $<0.001$ & 0.434 & $0.34 I-0.553$ \\
\hline
\end{tabular}

Note: aThis item is not included in the multivariable logistic regression.

Abbreviations: B, partial regression coefficients; Exp, exponential function; MSS, melanoma-specific survival; NM, nodular melanoma; OS, overall survival; SCM, spindle cell melanoma; SSM, superficial spreading melanoma.

Several factors such as age, tumor site, histologic type, TNM stage and so on were significantly associated with the rate of primary tumor surgery in unmatched cohort. To further corroborate the benefits of surgery found in univariate and multivariate analyses, we performed a propensity score matching to optimally adjust for the selection bias between the two groups (Table 1). As in the unmatched cohort, surgery of primary tumor was also associated with better OS (13 vs 6 months, $P<0.001$ ) and MSS (18 vs 6 months, $P<0.001)$ in the matched cohort (Figure 2).

\section{Discussion}

Metastatic melanoma has been an incurable disease in spite of the improvement in survival largely attributed to advances in systemic treatment options over the last decade, while the role of the primary tumor surgery in this setting is still ambiguous due to the lack of relevant research. To the best of our knowledge, this is the first study to evaluate the impact of primary tumor surgery on metastatic melanoma. Moreover, as the SEER database encompasses $28 \%$ of the US population, ${ }^{1}$ our data are, to some extent, generalized and reflective of the population experience.

Historically, the surgery in metastatic patients was generally referring to the surgery for metastatic sites (ie, the metastasectomy), which was performed for palliation or potentially cure. ${ }^{5}$ The National Comprehensive Cancer Network guideline ${ }^{26}$ recommends feasible metastasectomy in the patients with stage IV melanoma, but it does 
A

OS

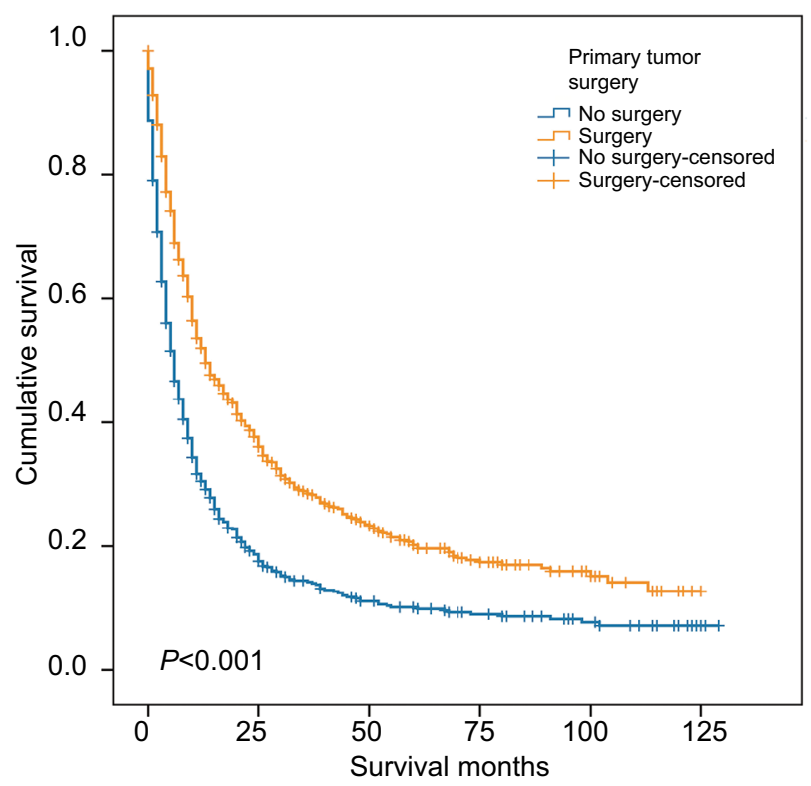

B

MSS

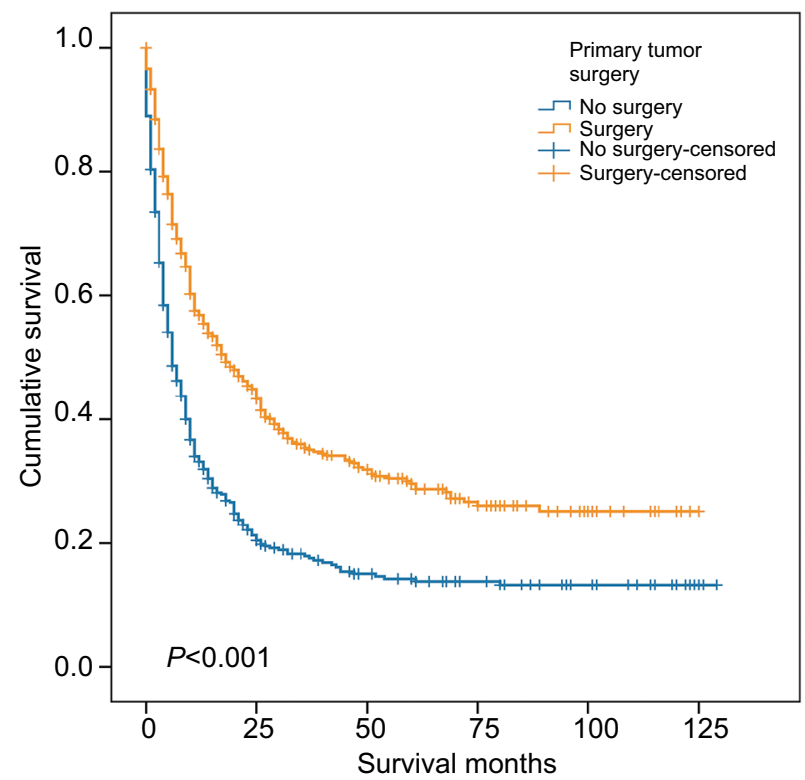

Figure 2 Kaplan-Meier curves for (A) OS and (B) MSS according to primary tumor surgery status in the matched cohort.

Abbreviations: MSS, melanoma-specific survival; OS, overall survival.

not describe whether primary tumor surgery should be performed in this population. The lack of attention to the primary tumor surgery in metastatic melanoma may be partly ascribed to the fact that most metastatic diseases occur when the primary tumor has already been removed in earlier treatment. Importantly, all stage IV patients from SEER are newly diagnosed cases, whose primary tumors and metastases coexist when diagnosed as cancer. In other words, their primary tumor has not been removed yet. This may explain why the rate of primary tumor surgery in this study was as high as $31 \%$, although the reasons for this or the guidelines followed by the US clinicians in the practice are unclear as far as we know. More importantly, both our results of Cox proportional hazard regression and analyses after propensity score matching demonstrated significant benefits of primary tumor surgery to OS and cancer-specific survival regardless of the patient, tumor and treatment characteristics. Although the results need to be further validated, they should call our attention to the benefit of primary tumor surgery in this population.

Similar to our investigation, several retrospective studies found that primary tumor surgery has a favorable prognostic impact on metastatic patients with other malignancies, such as breast, ${ }^{10-14}$ colorectal, ${ }^{15-17}$ gastric ${ }^{18-20}$ and renal cell cancer. ${ }^{21}$ Lowering the tumor burden, ${ }^{27,28}$ reducing recirculating tumor cells, ${ }^{29}$ decreasing the cytokines regulating tumor metastasis ${ }^{30}$ and restoring immunomodulation by removing potential source of immunosuppression from the primary site could explain the beneficial effect of primary tumor surgery. ${ }^{31}$ Considering the inherent selection biases in these studies and several controversial conclusions, ${ }^{32}$ and the theory of increased angiogenesis and accelerated relapse associated with surgical wound, ${ }^{33,34}$ the definitive effect and mechanisms of primary tumor surgery in these cancers and melanoma remain to be further clarified.

As we know, the targeted therapies and immune checkpoint inhibitors have been playing an vital role in treatment of metastatic melanoma since the US Food and Drug Administration approved BRAF V600E-targeted therapy and antiCTLA4 immunotherapy for this cohort of patients in the year $2011 .{ }^{35}$ We were confused by the fact whether the observed survival advantage in the surgical group was partly due to the effect of the novel agents mentioned above. As SEER does not provide the information whether patients have received the above treatments, we analyzed the effect of primary tumor surgery in pre (before 2011) and post (after 2011) the immune/targeted therapy periods, respectively. Also, we found that the surgery group had longer survival than the non-surgery group in both periods. Meanwhile, the COX regression analysis adjusted by the variables including time showed that surgery was a significantly independent prognostic factor, suggesting that the effect of surgery on survival 
may not be influenced by the targeted or immune therapy. Additionally, the SEER does not provide usable information of radiation and chemical therapy, which makes the adjustment impossible for the use of these treatments. Nonetheless, it seems unlikely that the significant effects of primary tumor surgery are due solely to unadjusted confounding.

In addition, we found that the proportion of the patients who received metastasectomy was only $2.1 \%$, which is much lower than that of patients receiving the primary tumor surgery. According to available evidence, metastasectomy was proved to be an effective treatment option with a benefit of OS for selected patients. ${ }^{5}$ Although metastasectomy was also associated with better survival in this study, its effect on improving the survival of metastatic population may be limited by the low proportion of the suitable candidates, ${ }^{4}$ which has been described by previous studies. ${ }^{35}$ Given the situation that the numbers of patients who had undergone primary tumor surgery and metastasectomy differed widely and more information was unavailable, the patients' selection for these two surgical methods or combined application should be further studied in well-designed clinical trials.

It is important to consider our study in the context of its limitations. Firstly, a bias due to the imbalance of the surgery group compared with the non-surgery group cannot be completely excluded, considering other potential prognostic factors, such as performance status, gene mutation status, the time between diagnosis and excision of the primary tumor, insurance status and so on, were not available in SEER. Secondly, the "unknown" subgroups of some variables included in the analysis may incur biases. Thirdly, we were not able to evaluate the impact of primary tumor surgery on the quality of life of patients because the information on complications or adverse reactions after surgery is not available in the SEER database.

\section{Conclusion}

Despite the limitations, this study reveals that primary tumor surgery significantly benefits both OS and MSS of patients with newly diagnosed metastatic melanoma. The results may fill in the gaps of the guidelines, but need to be validated by further prospective studies or trials.

\section{Acknowledgments}

This study was partially funded by Shandong Key Research and Development Plan (2017CXGC1209 and 2017GSF18164) and the Outstanding Youth Natural Sci- ence Foundation of Shandong Province (JQ201423), Jinan Clinical Medicine Science and Technology Innovation Plan (201704095), NSFC81372413 and National Key Research and Development Program of China (2016YFC0904700).

\section{Disclosure}

The authors report no conflicts of interest in this work.

\section{References}

1. National Cancer Institute Surveillance. Epidemiology, and End Results Program [homepage on the Internet]. SEER Stat Fact Sheets: Melanoma of the Skin. Available from: http://seer.cancer.gov/statfacts/html/melan. html. Accessed July 15, 2018.

2. Balch CM, Gershenwald JE, Soong SJ, et al. Final version of 2009 AJCC melanoma staging and classification. J Clin Oncol. 2009;27(36):6199-6206.

3. Gyorki DE, Yuan J, Mu Z, et al. Immunological insights from patients undergoing surgery on ipilimumab for metastatic melanoma. Ann Surg Oncol. 2013;20(9):3106-3111.

4. Wevers KP, Hoekstra HJ. Stage IV melanoma: completely resectable patients are scarce. Ann Surg Oncol. 2013;20(7):2352-2356.

5. Wollina U, Brzezinski P. The value of metastasectomy in stage IV cutaneous melanoma. Wiener medizinische Wochenschrift 2018. Available from http://scihub.tw/10.1007/s10354-018-0630-6. Accessed July 15, 2018.

6. Ugurel S, Röhmel J, Ascierto PA, et al. Survival of patients with advanced metastatic melanoma: the impact of novel therapies-update 2017. Eur J Cancer. 2017;83:247-257.

7. Schadendorf D, Fisher DE, Garbe C, et al. Melanoma. Nat Rev Dis Primers. 2015;1:15003.

8. Luke JJ, Flaherty KT, Ribas A, Long GV. Targeted agents and immunotherapies: optimizing outcomes in melanoma. Nat Rev Clin Oncol. 2017;14(8):463-482.

9. Pasquali S, Haydu LE, Scolyer RA, et al. The importance of adequate primary tumor excision margins and sentinel node biopsy in achieving optimal locoregional control for patients with thick primary melanomas. Ann Surg. 2013;258(1):152-157.

10. Rapiti E, Verkooijen HM, Vlastos G, et al. Complete excision of primary breast tumor improves survival of patients with metastatic breast cancer at diagnosis. J Clin Oncol. 2006;24(18):2743-2749.

11. Truong PT. Local treatment of the primary tumor in patients presenting with stage IV breast cancer: a first, and what's up ahead. Int J Radiat Oncol Biol Phys. 2017;97:443-446.

12. Shien T, Iwata H. Significance of primary lesion resection in Stage IV breast cancer. Jpn J Clin Oncol. 2017;47(5):381-384.

13. Warschkow R, Güller U, Tarantino I, et al. Improved survival after primary tumor surgery in metastatic breast cancer: a propensity-adjusted population-based SEER trend analysis. Ann Surg. 2016;263(6): $1188-1198$.

14. Lang JE, Tereffe W, Mitchell MP, et al. Primary tumor extirpation in breast cancer patients who present with stage IV disease is associated with improved survival. Ann Surg Oncol. 2013;20(6):1893-1899.

15. Søreide K. Resection of asymptomatic primary tumour in unresectable stage IV colorectal cancer: time to move on from propensity matched scores to randomized controlled trials. Int J Cancer. 2016;139(9):1927-1929.

16. Ferrand F, Malka D, Bourredjem A, et al. Impact of primary tumour resection on survival of patients with colorectal cancer and synchronous metastases treated by chemotherapy: results from the multicenter, randomised trial Fédération Francophone de Cancérologie Digestive 9601. Eur J Cancer. 2013;49(1):90-97.

17. Pędziwiatr M, Mizera M, Witowski J, et al. Primary tumor resection in stage IV unresectable colorectal cancer: what has changed? Med Oncol. 2017;34(12):188. 
18. Mariette C, Bruyère E, Messager M, et al. Palliative resection for advanced gastric and junctional adenocarcinoma: which patients will benefit from surgery? Ann Surg Oncol. 2013;20(4):1240-1249.

19. Müsri FY, Mutlu H, Karaağaç M, Eryilmaz MK, Gündüz Ş, Artaç M. Primary tumor resection and survival in patients with stage IV gastric cancer. J Gastric Cancer. 2016;16(2):78-84.

20. Warschkow R, Baechtold M, Leung K, et al. Selective survival advantage associated with primary tumor resection for metastatic gastric cancer in a Western population. Gastric Cancer. 2018;21(2):324-337.

21. Zhang CH, Pan YB, Zhang QW, et al. The influence of local therapy on the survival of patients with metastatic rectal cancer: a population-based, propensity-matched study. J Cancer Res Clin Oncol. 2017;143(9):1891-1903.

22. National Cancer Institute. Surveillance, Epidemiology, and End Results Program Program [homepage on the Internet]. Registry Groupings in SEER Data and Statistics. Available from: http://seer.cancer.gov/ registries/terms.html. Accessed July 15, 2018.

23. National Cancer Institute. Surveillance, Epidemiology, and End Results Program [homepage on the Internet]. Research Data (1973-2015), DCCPS, Surveillance Research Program, Surveillance Systems Branch, released April 2018, based on the November 2017 submission. Available from: www.seer.cancer.gov. Accessed July 15, 2018.

24. Little RJ, Rubin DB. Causal effects in clinical and epidemiological studies via potential outcomes: concepts and analytical approaches. Annu Rev Public Health. 2000;21(1):121-145.

25. Austin PC. An introduction to propensity score methods for reducing the effects of confounding in observational studies. Multivariate Behav Res. 2011;46(3):399-424.
26. NCCN, National Comprehensive Cancer Network [homepage on the Internet]. Guideline for Melanoma. Available from: https://www.nccn. org/patients/. Accessed July 15, 2018.

27. Khan SA, Stewart AK, Morrow M. Does aggressive local therapy improve survival in metastatic breast cancer? Surgery. 2002;132(4): $620-627$.

28. Khan SA. Surgery for the intact primary and stage IV breast cancer... lacking "robust evidence". Ann Surg Oncol. 2013;20(9):2803-2805.

29. Norton L. Cancer stem cells, self-seeding, and decremented exponential growth: theoretical and clinical implications. Breast Dis. 2008;29(1):27-36.

30. Takada T, Tsutsumi S, Takahashi R, et al. Control of primary lesions using resection or radiotherapy can improve the prognosis of metastatic colorectal cancer patients. J Surg Oncol. 2016;114(1):75-79.

31. Danna EA, Sinha P, Gilbert M, Clements VK, Pulaski BA, OstrandRosenberg S. Surgical removal of primary tumor reverses tumor-induced immunosuppression despite the presence of metastatic disease. Cancer Res. 2004;64(6):2205-2211.

32. Cirocchi R, Trastulli S, Abraha I, et al. Non-resection versus resection for an asymptomatic primary tumour in patients with unresectable stage IV colorectal cancer. Cochrane Database Syst Rev. 2012;8:CD008997.

33. Fisher B, Gunduz N, Coyle J, Rudock C, Saffer E. Presence of a growthstimulating factor in serum following primary tumor removal in mice. Cancer Res. 1989;49:1996-2001.

34. Gunduz N, Fisher B, Saffer EA. Effect of surgical removal on the growth and kinetics of residual tumor. Cancer Res. 1979;39:3861-3865.

35. Raigani S, Cohen S, Boland GM. The role of surgery for melanoma in an era of effective systemic therapy. Curr Oncol Rep. 2017;19(3):17.
Cancer Management and Research

\section{Publish your work in this journal}

Cancer Management and Research is an international, peer-reviewed open access journal focusing on cancer research and the optimal use of preventative and integrated treatment interventions to achieve improved outcomes, enhanced survival and quality of life for the cancer patient. The manuscript management system is completely online and includes

\section{Dovepress}

a very quick and fair peer-review system, which is all easy to use. Visit http://www.dovepress.com/testimonials.php to read real quotes from published authors. 